\title{
Firms' Altruism and Adoption of Solid Waste Management Practices in Sri Lankan Agri-Food Processing Sector: An Analysis Based on Panel Data
}

\author{
J. M. M. Udugama\# and U. K. Jayasinghe-Mudalige \\ Dept. of Agribusiness Management, \\ Faculty of Agriculture and Plantation Management, \\ Wayamba University of Sri Lanka, \\ Makandura, Gonawila (NWP), Sri Lanka \\ ${ }^{\#}$ Corresponding Author:
}

Tele: (94) 71832 9556; Fax: (94) 31229 9246; E-mail: menukaudugama@ gmail.com

\begin{abstract}
The specific objective of this study was to incorporate time dimensions into the empirical analyses carried out by Udugama et al. $(2009 ; 2011)$ with the motive of examining whether altruistic behavior of managers in agri-food processing firms in Sri Lanka has changed over time, and if so, whether it had an impact on firms' decision with respect to adoption of solid waste management practices (SWMPs) recommended by the Ministry of Environment of Sri Lanka. The data collected from a cross section of firms representative to the industry structure $(n=80)$ through a structured questionnaire administered with environmental managers/owners during March to June 2011 (Stage II) were matched with corresponding data collected two years earlier (Stage I) from the same set of firms (i.e. panel data) to formulate a Weighted Environmental Altruism Index (WEAI) reflecting the degree of altruism of a decision maker. The results suggest that environmental altruism of firms, as a whole, changed positively overtime, yet remains at a relatively low level (i.e. from 0.25 to 0.50 from Stage I and II, on an average, of the WEAI ranges from -1 to 1). In response, certain changes were evident to the level of adoption of 8 recommended SWMPs during this period (i.e. shift of Mean from 1.39 to 1.97) showing a positive relationship between altruism and firms private action on environmental management. The outcome of analysis emphasizes the importance of augmenting environmental altruism of decision-makers through better education and awareness creation alongside an incentive-based regulatory framework to increase the level of adoption of environmental controls so that firms are not liable for the environment it operates and to change the perspective of a firm's management beyond the profits towards sustainability.
\end{abstract}

KEYWORDS: Agri-food processing sector, Altruism, Environmental management, Panel data, Waste control 


\section{Introduction}

Unlike in the past, today, firms involve with various activities in the supply chain from production to marketing of goods and services claiming to be pursuing corporate environmental practices and strategies by engaging in self-regulated environmental management. The reasons for doing so may, however, vary from firm to firm; for example, they may engage to meet the existing legislative requirements and/or to foster environmental sustainability of the organizations. In fact, it has been the interest of researchers for a long time as to why some firms embrace environmentally responsive initiatives, while other firms in seemingly similar circumstances do not even comply with existing legislation.

The environmental economics and management literature points out two broad ways to maintain environmental quality such as: (1) the legal framework provided by the government and judiciary (i.e. public), and (2) the voluntary environmental protection, which is to be undertaken by a firm on its own willingness (i.e. private) (Hettige et al., 1996). Despite the conceptual frameworks developed (see, for example Kolstad et al., 1990; Rugman and Verbeke, 1998; Segerson and Miceli, 1998; Weersink et al., 1998) and empirical analysis carried out (Henriques and Sadorsky, 1996; Khanna, 2001; Nakamura et al., 2001) in the context of both developed and developing countries to discuss the effect of actions of both public and private institutions work in this respect, there exist significant differences with regard to private action by individual firms on environmental quality or the interplant variations in responses towards the adoption of enhanced environmental management controls at the level of firm. Social scientists, economists and psychologists insist that this behavior may be associated with the "degree of altruism" of the decision makers of the firm, yet have failed to elaborate this phenomenon in depth to date.

Altruism is defined, broadly, as the unselfish concerns for the welfare of others, or in other words, as an action that increases the welfare of others without regard for one's self interest. Environmental altruism is, thus, defined as making decisions and taking actions by the management of a firm with respect to environment that will ultimately augment the environment quality and its status (Kolm and Ythier, 2006). This shows that altruism is likely to play a particularly important role in people's attitudes and behavior when the issue of concern is a matter of collective interest where environmental issues are a prime concern in this domain. Altruistic behavior of a firm can, therefore, have a crucial impact on its private action towards maintaining the quality of its products and on the environment.

Bansal and Roth (2003) identified four drivers of corporate environmental response; (1) regulation; (2) stakeholder pressures; (3) economic opportunities, and (4) ethical motives or altruism. Environmental responsiveness, in this context, is not only driven by organizational-level determinants and regulations but also by the outcomes of environmental paradigms and/or belief systems of a manager. How 
these paradigms or belief systems, or in other words altruism, changes overtime has, however, not been explored empirically to date, to the best knowledge of authors, especially in the context of a developing country like Sri Lanka.

In a recent attempt to investigate this phenomenon in the context of Sri Lanka Udugama et al. (2009; 2011), empirically exploring the altruistic motives of agrifood processing firms to adopt solid waste management practices in the firm, concluded that there can exist a direct relationship between the degree of environmental altruism of a firm's decision maker/manager and its level of adoption of environmental management practices, proving this observable fact, the authors have further identified that, the managers of those large number of firms with zerocompliance to recommended solid waste management practices, possessed a relatively low degree of environmental altruism.

This particular study was aimed to incorporate the time dimension into the exploration carried out by Udugama et al. (2009; 2011) with the motive of examining whether altruistic behavior of managers in these firms operating in the agri-food processing sector has changed over time, and whether this change in turn, had an impact on their decision with respect to adoption of those recommended practices (see, Annex 1). It can, therefore be considered an analysis using panel data to observe the developments in the degree of altruism of managers versus firms' action towards environmental management, which is being examined, to the best knowledge of authors, for the first time in the context of the agri-good processing sector in Sri Lanka.

\section{Methodology}

\section{Derivation of Weighted Environmental Altruism Index}

To investigate the temporal changes in a firm on the given issue, it is of paramount importance to use panel data (i.e. data from the same set of firms in two different time periods). The same methodology used in Udugama et al. (2009; 2011) was, therefore, used in this study with slight adjustments and is summarized, in turn. The work completed and reported by Udugama et al. $(2009 ; 2011)$ is, therefore, considered as "Stage I" and further work with panel data is considered as "Stage II".

On the presumption that altruism is a behavioral concept which is directly unobservable and taking into considerations the facts explored in JayasingheMudalige and Henson (2006), we resolved to utilize a valid pertinent empirical measure to capture the degree of environmental altruism of the manager by formulating an index - "Environmental Altruism Index" (EAI) -which, in principle, satisfies the characteristics of an Additive Index (Powers and Xie, 1999) in the form of: 


$$
E A I_{i}=\sum_{i=1}^{n}\left[a\left(U_{S}\right)\right]_{i}
$$

Where, the term a $\left(\mathrm{U}_{s}\right)_{i}$ denotes the score given by a respondent $(i)$ to an attitudinal statement explaining various aspects/dimensions of environmental altruism of firm/manager $\left(U_{s}\right)$ [s = number of statements] on the likert-scale. Without any revision, the same set of statements used in Stage I $(\mathrm{s}=12)$ was used in Stage II to derive the EAI (see, Table 1).

The nature and extent to which a manager is perceived on the phenomenon explained in each attitudinal statement on his/her decision to adopt SWMPs in the firm was of specific interest. Therefore, each respondent was asked first to rate his/her perception on each statement in relation to the current performance of his/her firm on a two-point Likert scale, i.e., (1) agree ("yes"), or (2) disagree ("no"). Afterwards, he/she was instructed to rate the same statement on a five-point Likert-scale by taking into account the extent to which he/she agrees (if they say "yes" in the $1^{\text {st }}$ rating) or disagrees (if they say "no" in the $1^{\text {st }}$ rating) with this particular statement (Oppenheim, 1992).

The summation of scores provided by a firm to all the statements, i.e. $\mathrm{s}=12$ in this analysis, was then divided by the Maximum Potential Score (MPS) [i.e. $a\left(U_{s}\right)$ ] in order to normalize the value of index, i.e. $\left[\mathrm{a}\left(\mathrm{U}_{\mathrm{s}}\right)\right]=60$, as the analysis used a fivepoint likert-scale for the 12 statements thus is the highest value a respondent can obtain if he/she is extremely altruistic on the phenomenon explained in all statements [i.e. "yes" $(=1)$ and then +5 for all statements). With the normalization, the values of EAI for a given firm, thus, ranges from -1 to 1 , where -1 reflects the "perfect non-altruism" of the decision maker on environment quality [i.e. "no" $(=0)$ and then -5 for all statements with MPS of -60$)$, and 1 on the other extreme reflects the "perfect altruism" [i.e. "yes" $(=1)$ and then +5 for all statements with MPS of $60)$.

The scores provided on statements were tested for unidimensionality ${ }^{1}$, since, logically, all the statements stated originally may be confined to a single variate (Hair et al, 1998). However, all respondents may not value the underlying phenomenon explained in a given statement as "equally important" for them to be altruistic towards the environment. Given this, it is imperative to incorporate this variation into the analysis. To fulfill this condition, following Udugama et al. (2009; 2011), the original EAI was extended to a "weighted" EAI - herein referred to as WEAI, which is expressed as:

\footnotetext{
${ }^{1}$ By eliminating the empirical issues associated with quantifying attitudes and perceptions of people, including the endogeneity, mutual exclusivity, subjectivity and unobservability through the testing for their unidimensionality (Buchanan, 1969; Hair et al., 2006; Nakamura et al., 2001).
} 


$$
W E A I_{i}=\sum_{i=1}^{n} W_{s}\left[a\left(U_{S}\right)\right]_{i}
$$

where, all parameters are equal to those given in the EIA equation expressed earlier and $\mathrm{W}$ represents the weight assigned to each statement to characterize the variation of responses of respondents.

\section{Data Collection \& Analysis}

The data pertaining to the Stage I was obtained from SANDEE Database used in Jayasinghe-Mudalige and Udugama (2010) that includes the primary data on numerous aspects related to a firm's performance on environmental quality management of 325 agri-food processing firms in Sri Lanka belonging to five different sub-sectors ${ }^{2}$. Given the time and budgetary constraints, we have resolved to select only 40 percent of firms participated to Stage I to carry out the Stage II of the study.

A sample of 130 food processing firms representative to the industry structure observed in Jayasinghe-Mudalige and Udugama (2010) and located in three provinces [i.e., Western (WP), North Western (NW) and Central (CP)] were, in turn, selected for the analysis in Stage II. To support the analysis based on firmspecific characteristics, the classification used in Stage I to reflect firm size was retained which took into account firm's annual sales value for this purpose, namely: (a) "Small" (Rs. 100,000 - 500,000), and (b) "Large" (>Rs. 500,000).

The gap between Stage I and Stage II to contact a firm to collect data was set to a minimum of two years so that the firm possesses sufficient time to reallocate its resource base to come up with appropriate environmental controls as a solution to manage solid waste it generates and the relevant staff may undergo training/learning process on environmental responsiveness. The data for Stage II were, therefore, collected during March and June 2011. The firms selected to the sample were informed, in prior, about the study, and more specifically, about their contribution to the Stage I and the importance of participation to the Stage II in which each firm's progress on this issue is investigated. A letter of request for an appointment together with the summary of outcome of Stage I was sent to all selected firms, and was simultaneously contacted over the phone. During the preliminary screening of the firms, we have identified that certain firms selected into the sample were not in operation (i.e. plant-exit) or under-operation (i.e. partial-exit) and/or the ownership/management has changed from Stage I.

\footnotetext{
${ }^{2}$ Five sub-sectors based on the type of product [i.e. processed fruits and vegetables (PFV)]; coconut products (COP); essential oils (ESO); non-alcoholic beverages (NAB), and other processed products $(\mathrm{OPP})]$.
} 
With all efforts, the collection of data was confined to 80 firms, and others were excluded from the sample due to various reasons such as; the management was busy during the period of contact with his/her day-to-day operations; not interested on this issue anymore, i.e. does not like to explore the current situation of the firm, confidentiality of information, the outcome of Stage 1 has no direct implications on the firm etc., which were recorded very often as common issues pertaining to collection of data on sensitive issues like environment and food quality in the firms, especially operating in developing countries (Hettige et al., 1996; Pargal and Wheeler, 1996).

A face-to-face interview supported by the structured questionnaire ${ }^{3}$, which is slightly deviated from the format used in Stage I, followed by an inspection of the site for the cases where permission was granted, was carried out with the same person that responded to the Stage I, or in cases where the same person was not in position (i.e. resign, busy, change position etc.), the top-most executive who possess executive powers to make decisions with respect to environmental quality at the point of contact to collect data. Like in Stage I, the respondent was asked to report the current situation of the firm with regard to the status of adoption of each recommended solid waste management practice explained in Annex 1 based on four different criteria expressing the level of adoption, namely: (1) "No plans" to implement; (2) "Possesses a plan" to implement; (3) "Is in the process" of implementing; and (4) "Has already adopted", the particular SWMP in question.

The data collected from each firm in Stage II were coded in a database, which was derived from the original SANDEE database with the corresponding data from Stage I to facilitate panel data analysis ${ }^{4}$. Like in Stage I, the first step towards analysis was to make sure whether all statements were condensed into a single factor, i.e. unidimensionality. The Principal Component Analysis (PCA) was employed to test this condition ${ }^{5}$. The relative weight $(\mathrm{W})$ of each statement were estimated $^{6}$ for both Stage I and II to make comparisons to show the relative importance of phenomenon explained by each statement presented to firms in the

\footnotetext{
${ }^{3}$ See, Jayasinghe-Mudalige and Udugama (2010).

${ }^{4}$ The sample in Stage II represents nearly $25 \%$ of the original sample (i.e. $80 / 325 \times 100$ ) that satisfies the requirements for a meaningful analysis that use panel data.

5 PCA is an interdependence technique stated under the Multivariate Data Analysis technique that is used commonly to define the underlying structure among a set of variables of an analysis objectively. This helped particularly to find a way to condense the information contained in these 12 statements (i.e. original variables) into "single variate (factor)" or if not into a "smaller set of new composite dimensions or variates" with a minimum loss of information by taking into account of the total variance amongst the original variables (Hair et al., 2006).

${ }^{6}$ First, the Summation of Scores $\left(\mathrm{SS}_{\mathrm{a}}\right)$ provided by all respondents in the sample to a given statement was taken and the weight to be assigned to each statement was decided upon the size of $\mathrm{SS}_{\mathrm{a}}$ accordingly. As a result, a relatively large weight was assigned to any statement that obtained a large $\mathrm{SS}_{\mathrm{a}}$.
} 
two different time periods. To elicit the differences on altruistic behavior of firm's decision maker and his/her action on adoption of environment management practices over the two periods of time in concern, comparisons were made using the values derived WEAI as it reflects relatively the true nature of the change, where the firm size is of particular interest. 


\section{Results and Discussion}

\section{Level of Adoption of Recommended SWMPs}

The sample of 80 firms comprised of 55\% Large and 45\% Small firms. With regard to the type of SWMPs adopted by firms, it was observed that "Good Manufacturing Practices", "Composting" and "3R system" were the most popular amongst the firms, while only a small percentage of firms adopted the rest of the recommended practices. It is of interest to examine the changes took place between Stage I and II with regard to the degree of adoption of SWMPs and the motives behind. As shown in Figure 1, in Stage I, GMP was the most popular practice amongst the firms with an adoption rate of 36 percent followed by 28 and 26 percent of firms adopting Composting and a 3R system, respectively. These percentages were seen to have increased considerably in Stage II with 61, 46 and 33 percent of firms, respectively, adopting GMP, Composting and a $3 \mathrm{R}$ system.

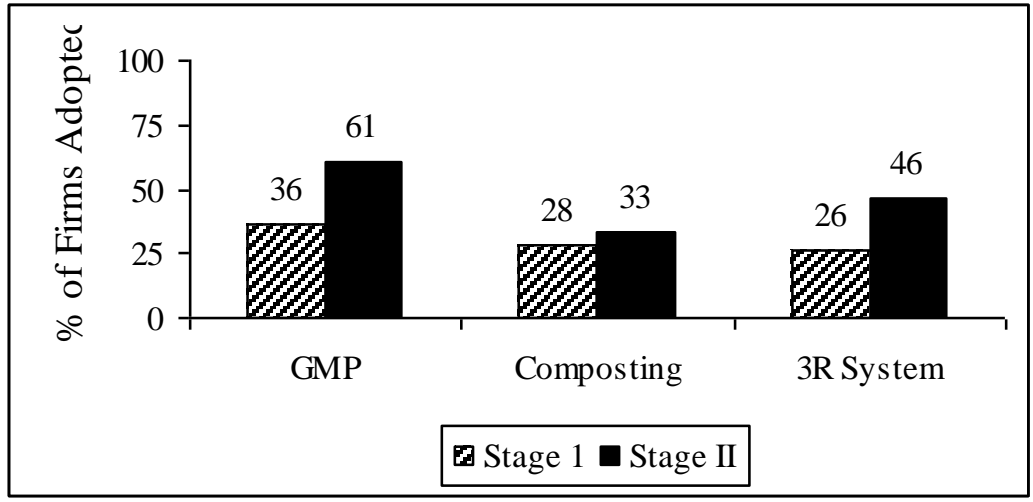

Figure 1: Level of adoption of the most popular SWMPs

A considerable increase to the total number of practices adopted by a firm was also detected from Stage I to Stage II (i.e. Mean level of SWPMs adopted in Stage I and II was 1.39 and 1.97). As shown by the left-skewed distribution curve in Figure 2a, during Stage I, about 44 percent of the firms did not possess any of the recommended practices. However, Figure 2a clearly depicts that this percentage dropped to 16 percent in Stage II.

Further, only 25, 13 and 2 percent of firms adopted one, two or three out of the eight practices recommended, respectively, in Stage I. These percentages, respectively, have been changed to 23, 33 and 20 in Stage II creating a shift in the distribution curve to the right. However, it was evident that in Stage II, the firms that adopted more than 4 practices have chosen to operate with lesser number of practices by shifting to the most cost effective and sustainable practices rather than maintaining several different practices in place. 


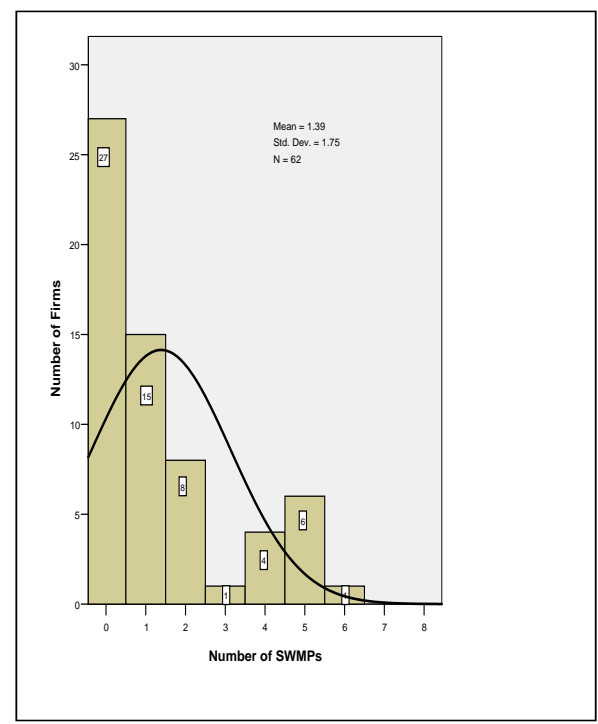

Figure 2a: No. of SWMPs in Stage I

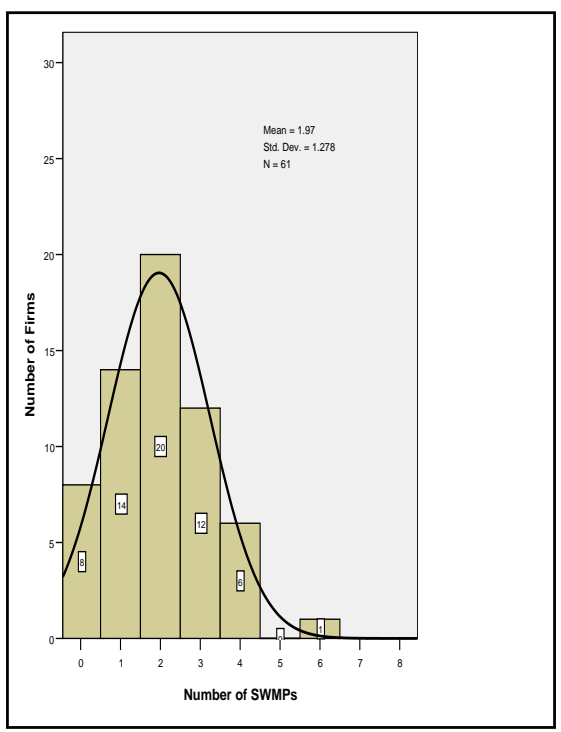

Figure 2b: No. of SWMPs in Stage II

Figure 2: Number of SWMPs adopted by the firms

Interestingly, the number of SWMPs adopted by a firm varied to a greater extent vis-à-vis the type of the firm and its size. With regard to firm size, large firms, not surprisingly, tended to adopt a higher number of SWMPs. For example, nearly 20 percent of large firms adopted more than 4 such practices in plant, compared to 67 percent of small firms who did not adopt a single practice in Stage I. By Stage II, an evident increase of 47 percent was shown by the large firms while the small firms without a single with zero adoption have decreased to 49 percent indicating a move towards higher environmental responsiveness. The firms that did not adopt any of these practices, or in other words indicated zero adoption, were classified into three categories as: (1) in the process of adoption; (2) plan to adopt within three years (i.e. from the point of time in Stage I), and (3) do not possess plans to adopt within three years time. It was observed that with regard to the adoption of most popular practices in Stage I (i.e. GMP, Composting, 3R system), as a whole, 16 percent of firms belonging to category 3 above in Stage I had moved into the category 1 or 2 by Stage II denoting a positive drive towards adoption (Figure 3).

\section{Mean Value of the Attitudinal Statements}

With the presumption that the firms' behavioral change is guided to a greater extent by the change in their altruism, it was essential to assess the extent to which respondents, on an average, perceived on the effect of individual statements reflecting environmental altruism. The Mean score of each statement was estimated for both Stage I and II (Table 1; Figure 4). 


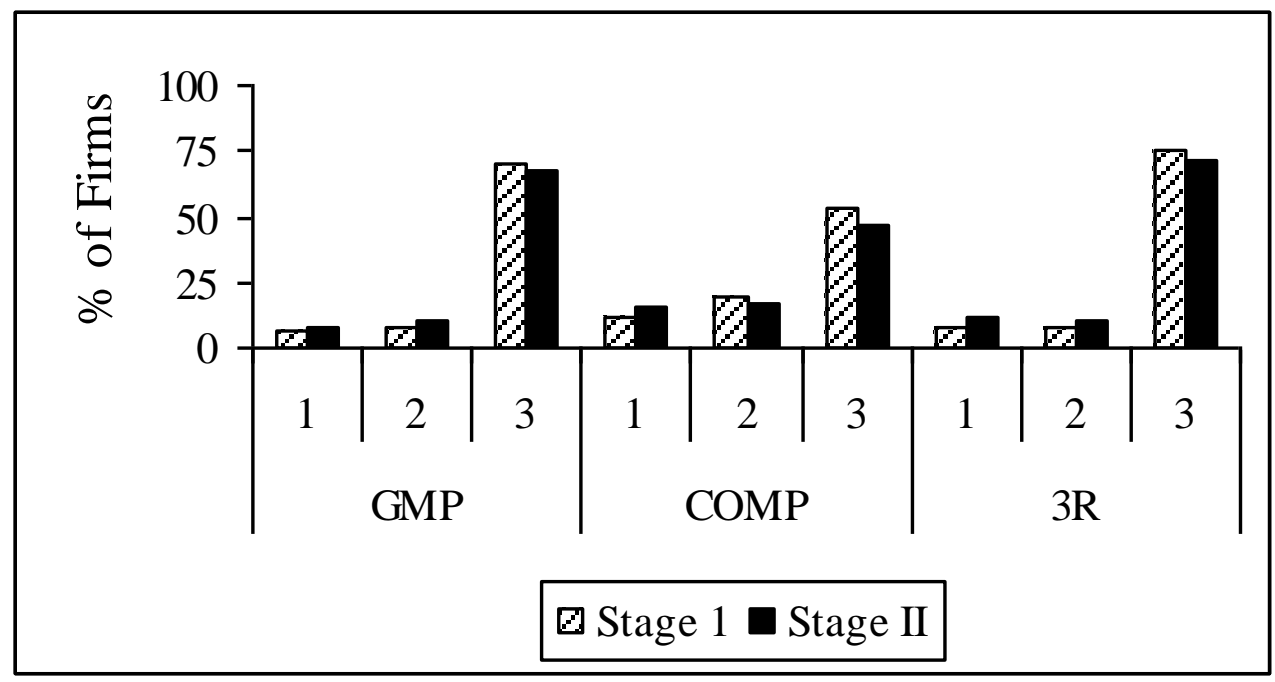

Figure 3: Status of Non-adopters of any SWMP

According to the results, the highest Mean score in Stage I and II was obtained for the statements $\mathrm{U}_{12}$, i.e. 3.31 and 3.74 , respectively, by the large firms and 2.93 and 4.93 , respectively, by the small firms. The change in the mean scores over the two periods denotes a clearer picture. Figure 4 denotes that the small firms recorded the highest positive change for $\mathrm{U}_{12}$ (i.e. 3.74 to 4.93 ) implying that they feel it is their personal responsibility to ensure that the firm to which they serve for should improve its environmental performance.

The most negative change was seen for $\mathrm{U}_{10}$. This may be due to the fact that being small firms with relatively low rates of waste generation, compared to the larger ones; they were not willing to pay a "price" for pollution under the view that the disposal is minimal or manageable within the firms. The larger firms indicated the highest positive change for $\mathrm{U}_{9}$ stating that they were taking the best possible measure to mange waste which makes the firm's contribution to environmental pollution is small and hardly makes a difference and that they were only ready to pay a fine in case the threshold levels exceed for the sake of minimizing pollution.

Interestingly, the highest difference was recorded for $\mathrm{U}_{11}$ by these firms where this negative change highlights a key relationship with the altruism. Though they initially believed that environmental damage is part and parcel with the economic growth by now they are of the view that the growth should be complementary but not competitive with the environment which sheds a strong behavioral change towards environmental sustainability. Taken as a whole, it was evident that irrespective of the firm size, all statements have shown positive increments in the scores provided, especially for the smaller ones, which may have guided higher adoption rate within these firms. 
Table 1: Mean scores of attitudinal statements

\begin{tabular}{|c|c|c|c|c|c|c|c|}
\hline & \multirow[t]{2}{*}{ Attitudinal Statement } & \multicolumn{2}{|c|}{ Stage 1} & \multicolumn{2}{|c|}{ Stage II } & \multicolumn{2}{|c|}{$\begin{array}{c}\text { Difference } \\
\text { (Stage I to II) }\end{array}$} \\
\hline & & $\mathbf{S}$ & $\mathbf{L}$ & $\mathbf{S}$ & $\mathbf{L}$ & $\mathbf{S}$ & $\mathbf{L}$ \\
\hline $\mathrm{U}_{1}$ & $\begin{array}{l}\text { Many top managers in my firm are } \\
\text { personally and actively involved in } \\
\text { developing environment protection } \\
\text { policies and monitoring their } \\
\text { implementation. }\end{array}$ & -1.41 & 1.66 & 3.46 & 3.29 & +4.87 & +1.63 \\
\hline $\mathrm{U}_{2}$ & $\begin{array}{l}\text { My Company has a written } \\
\text { environmental policy that states } \\
\text { goals for improving our } \\
\text { environmental performances. }\end{array}$ & 0.44 & 1.60 & $0 . \overline{85}$ & 0.20 & -1.29 & -1.4 \\
\hline $\mathrm{U}_{3}$ & $\begin{array}{l}\text { Clear and strong signal has been } \\
\text { sent from our top managers that } \\
\text { better environmental management is } \\
\text { a requirement in our firm, not a } \\
\text { choice. }\end{array}$ & 1.15 & 2.69 & 3.38 & 3.63 & +2.23 & +0.94 \\
\hline $\mathrm{U}_{4}$ & $\begin{array}{l}\text { My firm has a long term plan to } \\
\text { lower our pollution control costs in } \\
\text { order to be more competitive in the } \\
\text { market. }\end{array}$ & 0.63 & 2.80 & 2.96 & 2.26 & +2.33 & -0.54 \\
\hline $\mathrm{U}_{5}$ & $\begin{array}{l}\text { Environmental protection is an } \\
\text { integral part of my company's } \\
\text { culture. }\end{array}$ & 0.26 & 2.40 & 4.15 & 3.43 & +3.89 & +1.03 \\
\hline $\mathrm{U}_{6}$ & $\begin{array}{l}\text { Ideas on pollution management are } \\
\text { shared freely among lower, middle, } \\
\text { and upper levels within my firm. }\end{array}$ & -1.37 & 2.06 & 2.69 & 2.94 & +4.06 & +0.88 \\
\hline $\mathrm{U}_{7}$ & $\begin{array}{l}\text { Humans have the right to modify the } \\
\text { natural environment to suit their } \\
\text { needs. }\end{array}$ & 0.78 & 0.49 & 1.04 & 1.89 & +0.26 & +1.40 \\
\hline $\mathrm{U}_{8}$ & $\begin{array}{l}\text { Advances in technology will } \\
\text { eventually solve the problem of } \\
\text { environmental degradation. }\end{array}$ & -2.67 & 1.00 & $\overline{-} 88$ & -1.97 & +1.79 & -2.97 \\
\hline $\mathrm{U}_{9}$ & $\begin{array}{l}\text { My firm's contribution to } \\
\text { environmental pollution is small and } \\
\text { hardly makes a difference. }\end{array}$ & -1.63 & -1.14 & 0.08 & 0.80 & +1.71 & +1.94 \\
\hline $\mathrm{U}_{10}$ & $\begin{array}{l}\text { Polluters should pay fully for the } \\
\text { damage they cause, and be } \\
\text { responsible for cleaning up their } \\
\text { pollution. }\end{array}$ & 3.26 & -0.89 & 2.00 & 1.01 & -1.26 & +1.90 \\
\hline $\mathrm{U}_{11}$ & $\begin{array}{l}\text { A certain amount of environmental } \\
\text { damage is tolerated if there is to be } \\
\text { economic growth. }\end{array}$ & 2.93 & 3.26 & 0.42 & -0.83 & -2.51 & -4.09 \\
\hline $\mathrm{U}_{12}$ & $\begin{array}{l}\text { I feel it is my personal responsibility } \\
\text { to ensure that my organization } \\
\text { improves its environmental } \\
\text { performance. }\end{array}$ & -1.41 & 3.31 & 4.58 & 3.74 & +5.99 & +0.43 \\
\hline
\end{tabular}




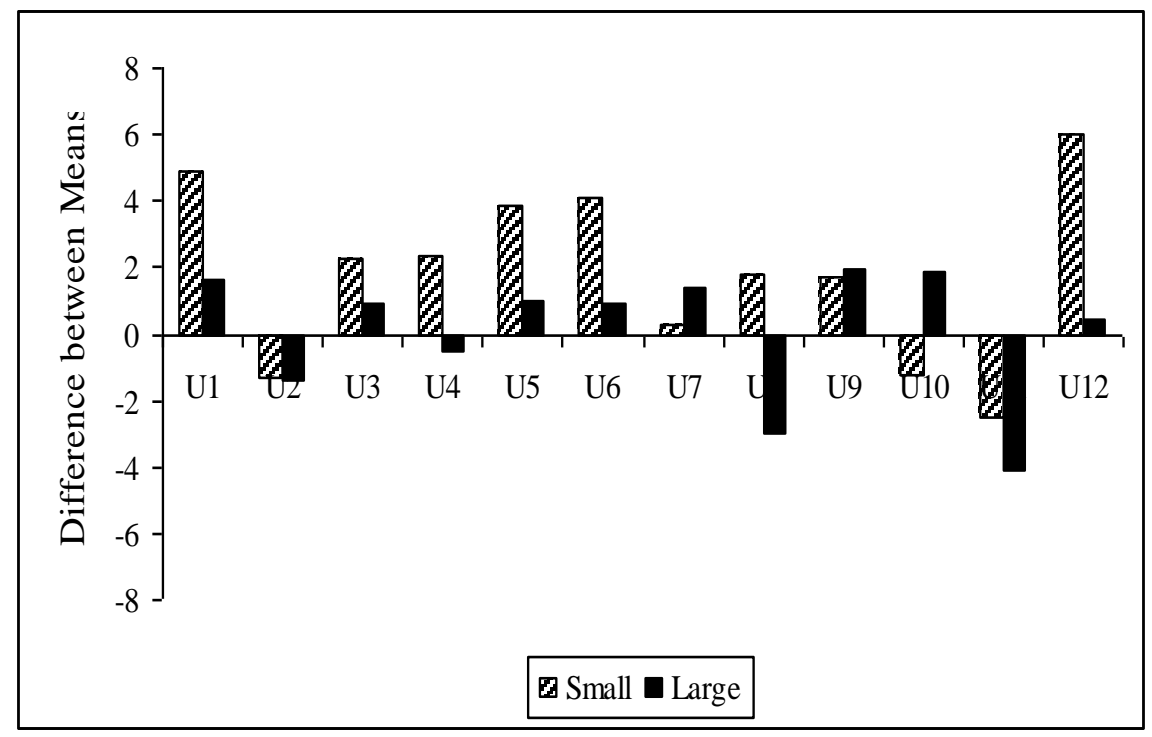

Figure 4: Changes to the mean response value of statements

\section{Estimates of Environmental Altruism Index}

We followed the procedure explained in Udugama et al. $(2009 ; 2011)$ to derive WEIA. The first step towards that was to obtain respective weights for the attitudinal statements. Principal Component Analysis was carried out with the data from Stage I and Stage II to facilitate obtaining weights (Table 2). While there is no rigorous criterion specified to assess when factor loadings are significant, Spector (1992) suggests that a minimum value of around $0.30-0.35$ indicates that an Indicator loads onto a factor, thus unidimensionality condition is satisfied.

The outcome of PCA clearly shows that in Stage I, all statements used to assess environmental altruism in this analysis were condensed into two factors, while in Stage II, they were classified into five factors. This phenomenon draws attention to the fact that mangers' perception on altruism has varied considerably within the period of years. This incongruence may have been due to the inability of executing the intended or desired environmental controls or due to some other a latent behavioral factor which is yet to be explored.

The values obtained for WEIA show that, irrespective of the firm size and temporal difference, they lie between a very narrow range between a +0.5 to -0.5 surprisingly indicating that although the statements have shown increments on an average, the degree of environmental altruism among the managers is relatively low (Figure 5). Nevertheless, irrespective of the firm size, it was observed all statements on an average showed relatively positive values. Proving the facts from the analysis 
above, it was seen that the smaller firms indicated the highest shift in their altruism while the larger firms did not indicate a significant shift.

Table 2: Mean values of the attitudinal statements

\begin{tabular}{|c|c|c|c|c|c|c|c|c|c|}
\hline \multirow{3}{*}{$\begin{array}{l}\text { Attitudinal } \\
\text { Statement }\end{array}$} & \multirow{2}{*}{\multicolumn{2}{|c|}{$\begin{array}{c}\text { VRFL } \\
\text { Stage I } \\
\text { Factor }\end{array}$}} & \multirow{3}{*}{ COM } & \multicolumn{5}{|c|}{$\begin{array}{c}\text { VRFL } \\
\text { Stage II } \\
\end{array}$} & \multirow{3}{*}{$\begin{array}{c}\text { CO } \\
\mathbf{M}\end{array}$} \\
\hline & & & & \multicolumn{5}{|c|}{ Factor } & \\
\hline & 1 & 2 & & 1 & 2 & 3 & 4 & 5 & \\
\hline $\mathrm{U}_{1}$ & 0.75 & 0.40 & 0.72 & 0.58 & 0.00 & 0.38 & 0.14 & -0.25 & 0.57 \\
\hline $\mathrm{U}_{2}$ & 0.72 & 0.52 & 0.80 & 0.13 & 0.36 & 0.28 & 0.62 & 0.04 & 0.61 \\
\hline $\mathrm{U}_{3}$ & 0.74 & 0.40 & 0.72 & 0.21 & 0.26 & 0.58 & 0.03 & 0.31 & 0.55 \\
\hline $\mathrm{U}_{4}$ & 0.75 & 0.48 & 0.79 & 0.06 & -0.12 & 0.02 & 0.85 & 0.03 & 0.74 \\
\hline $\mathrm{U}_{5}$ & 0.69 & 0.53 & 0.77 & 0.69 & 0.00 & -0.11 & 0.29 & 0.29 & 0.66 \\
\hline $\mathrm{U}_{6}$ & 0.83 & 0.29 & 0.78 & 0.51 & 0.02 & -0.24 & 0.42 & -0.30 & 0.60 \\
\hline $\mathrm{U}_{7}$ & 0.59 & 0.61 & 0.73 & -0.10 & 0.75 & 0.12 & 0.06 & -0.06 & 0.61 \\
\hline $\mathrm{U}_{8}$ & 0.73 & 0.02 & 0.53 & -0.02 & -0.09 & -0.03 & 0.02 & 0.89 & 0.80 \\
\hline $\mathrm{U}_{9}$ & 0.52 & 0.61 & 0.64 & -0.12 & -0.06 & 0.79 & 0.08 & -0.15 & 0.67 \\
\hline $\mathrm{U}_{10}$ & 0.37 & 0.46 & 0.35 & 0.02 & 0.77 & -0.22 & -0.05 & -0.16 & 0.68 \\
\hline $\mathrm{U}_{11}$ & -0.05 & 0.90 & 0.81 & -0.06 & -0.51 & -0.31 & -0.02 & -0.27 & 0.44 \\
\hline $\mathrm{U}_{12}$ & 0.80 & 0.10 & 0.65 & 0.84 & -0.04 & 0.03 & -0.10 & 0.00 & 0.73 \\
\hline
\end{tabular}

Note: $\mathrm{VRFL}=$ Varimax-Rotated Factor Loadings; $\mathrm{COM}=$ Communalities

To obtain a clearer picture of the variation in their perception reflected by the index values, the percentage change of the index value for each statement was calculated for both large and small firms (Figure 6).

The results highlight that, although the mean index values did not indicate a significant difference, the percentage change of each statements denoted that firms perceived the underpinning scenarios/circumstances variably depending on the firm size. It was evident that the large firms possessed a firm-centric view. The larger firms showed the highest positive percentage change for the statement $U_{7}$ which says: "humans have the right to modify the natural environment to suit their needs" while most negative percentage change was shown for $\mathrm{U}_{10}$ : "polluters should pay fully for the damage they cause, and be responsible for cleaning up their pollution". This highlights that large firms believed that, if needed, the environment can be modified to suit the needs of the firm to carry out its operations.

As these firms generate more waste comparatively, the positive change in index values for all statements, on an average, from Stage I to Stage II, shows that their altruism towards the environment has increased, on an average, overtime. Nevertheless, they were not willing to pay for the damage caused signaling such policies/regulations are not welcome by the agri-food sector. This does not imply 
that their altruism was any less different from what it was few years back but instead of compensating the pollution in monetary terms the trade off would be to act voluntarily towards adoption of the environmental management practices.

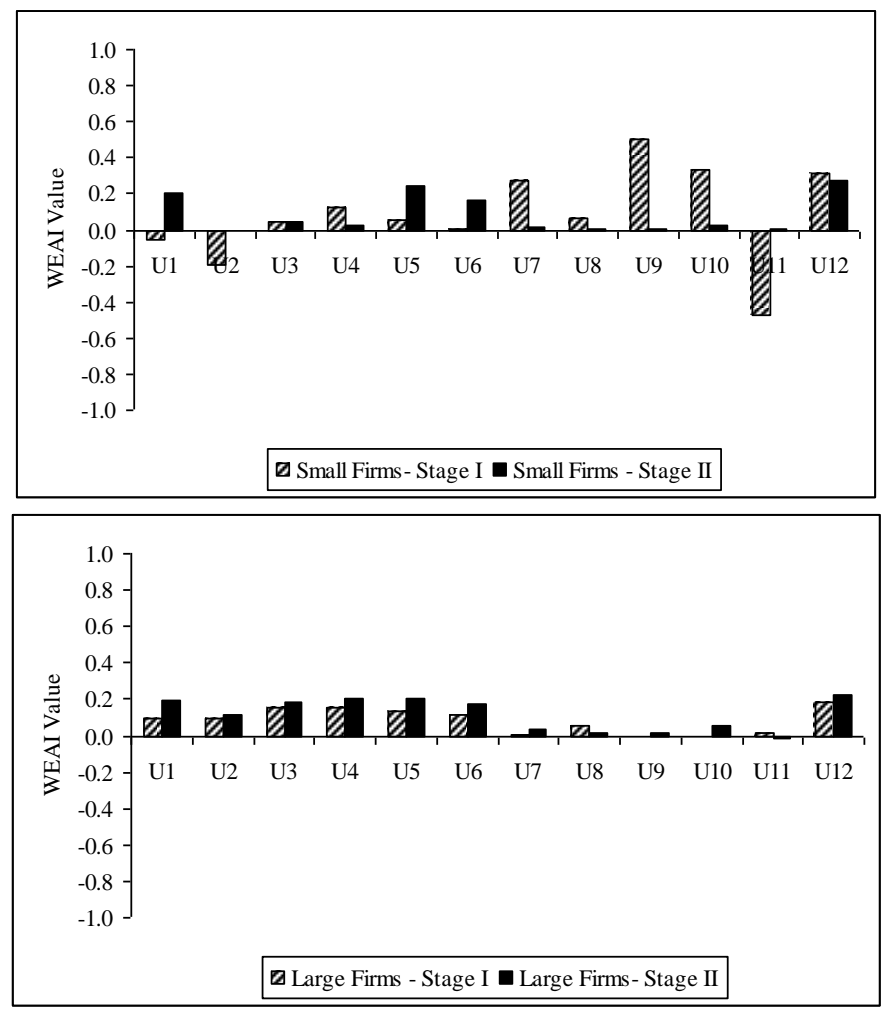

Figure 5: Changes in WEAI from Stage I to II 


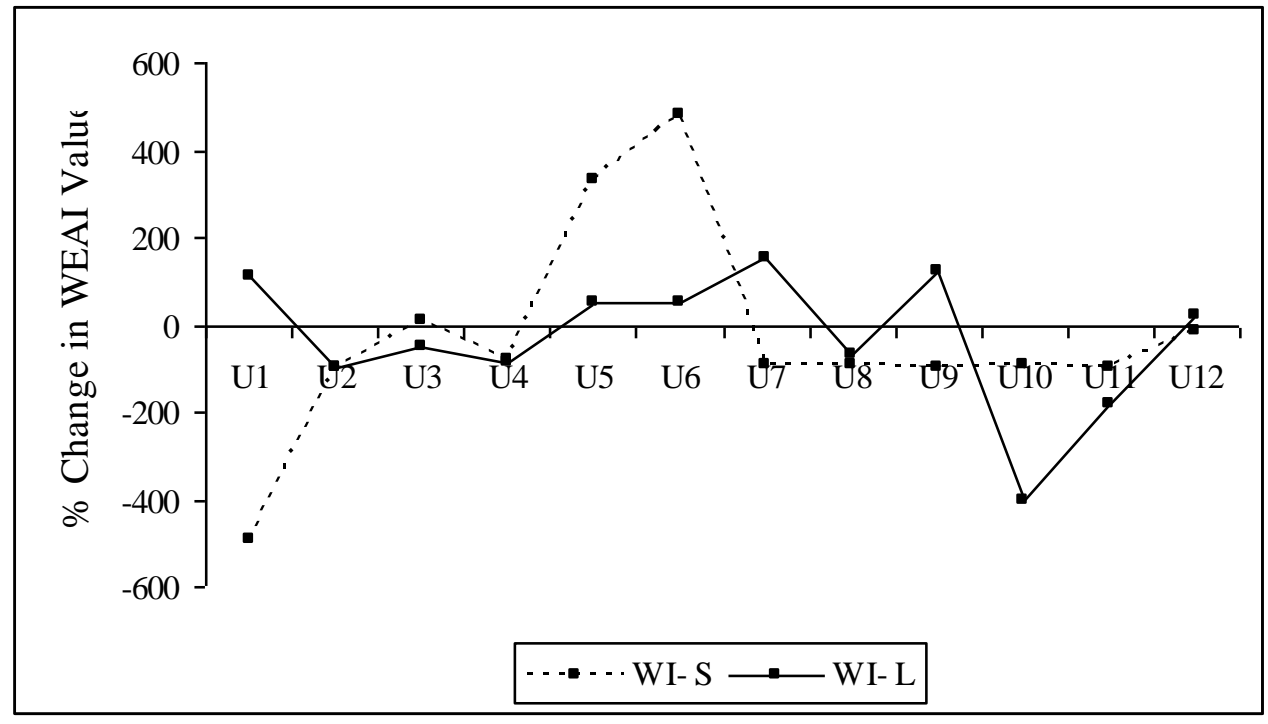

Figure 6: Percentage change in WEAI values from Stage I to II

Where smaller firms are of concern, contrastingly, the highest positive change was seen in $\mathrm{U}_{6}$ which implies that awareness on pollution management are shared freely among lower, middle, and upper management levels within their firm than the earlier. During the Stage I of the study, one of the limiting factors of adoption was the fact that the employers let alone the employees were not aware of the information on the recommended practices. This highlights the correlation between information and the shift towards adoption or the reduction in the rate of non adoption to a greater extent. The most negative change was seen in $U_{1}$. This is much anticipated as being a small firm with less regulatory enforcement and lack of other incentives, the top management may not prioritize on environmental control though the managers are altruistically motivated.

\section{Conclusions and Policy Implications}

The outcome of analysis highlights the fact that altruistic behavior of the decision maker of a firm has evidently changed over time. The analysis emphasizes that the environmental responsiveness of agri-food processing firms, in general, which is reflected by the adoption of the SWMPs, is associated with this observed change in the altruistic behavior of the management of the firm. The given period of three years, in an economic sense is not long enough to make a drastic change in human behavior which could be reflect by a complex action as the adoption of environmental control systems. 
However, the increased rate of the number of practices which reflects environmental responsiveness underpins a change in behavior, guided by a latent phenomenon which we believe to be their altruism or unselfish concerns. The outcome of analysis insists that the government, together with the other sectors in the market (such as industry and trade organizations) should assist the firms to develop appropriate environmental quality management programs coupled with extensive training to enhanced their awareness on the environment. Trade and other industry organizations, as an integral part of the market can play an extensive role in this connection to make use of a firm's resource base most effectively in this respect, and for that purpose, it is needed to reward the self-motivated managers regularly for their altruistic behavior on environmental quality.

The study further emphasizes that the fragmented environmental responsiveness of managers could also be due to the fact that environmental issue is evaluated incrementally and often independently of other issues faced by firms existing in the developing country context. This may also be the fate of their actions not being propelled up by other incentives or fueled by legislation. Observably, if individual concerns are translated into initiatives motivated by environmental responsibility, a futuristic firm is additionally motivated by anticipated competitive advantage which would easily be propelled by their self regulation over time.

Apparently, coercive pressures through legislation are currently not stringent in the context of Sri Lanka with regard to adoption of the SWMPs in the agri-food processing firms. Nevertheless, the study reflects that bona fide intentions, at least at the individual level of managers, regarding future development of environmental sustainability, as many of the respondents expressed strong endorsement of the environmental paradigms implying optimism towards self regulated environmental responsiveness in the future.

\section{Acknowledgement}

We acknowledge the financial assistance provided by the South Asian Network for Development and Environmental Economics (SANDEE) (Stage I) and the Wayamba University of Sri Lanka for the Competitive Research Grant Scheme (SRHDC/RP/01/10-01) (Stage II) to carry out this study. Also, the technical assistance given by Mr. Dharshana Attanayake, Ms. G. H. I. Anjali, Mr. S. M. M. Ikram and Ms. Tharanga Herath is highly appreciated.

\section{References}

Bansal, P. and K. Roth (2000). "Why companies go green, a model of ecological responsiveness" Academy of Management Journal, 43(4): 717-737.

Buchanan, J. M. (1969). "Cost and choice: an inquiry in economic theory" Markham, Chicago. 
Hair, J. F., R. E. Anderson., R. L. Tatham and W. C. Black (1998). "Multivariate data analysis. $5^{\text {th }}$ Ed. Prentice-Hall, New Jersey.

Henriques, I. and P. Sadorsky (1996). "The determinants of an environmental responsive firm: an empirical approach" Journal of Environmental Economics and Management, 30: $381-395$.

Hettige, H., M. Huq, S. Pargal and D. Wheeler (1996). "Determinants of pollution abatement in developing countries: evidence from South and Southeast Asia" World Development, 24: 1891-1904.

Jayasinghe-Mudalige, U. K. and S. Henson (2006). "Economic incentives for firms to implement enhanced food safety controls: case of the Canadian red meat and poultry processing sector" Review of Agricultural Economics, 28(4): 495-514.

Jayasinghe-Mudalige, U. K. and J. M. M. Udugama (2011). "Motives for firms to adopt solid waste management controls: the case of food processing sector in Sri Lanka". Working Paper No 60-11 (ISSN 1893-1891), South Asian Network for Development and Environmental Economics (SANDEE).

Khanna, M. (2001). "Economic analysis of non-mandatory approaches to environmental Protection" Natural Resources, 4: 42-46.

Kolm, S. and J. M. Johnson (2006). "Handbook of the economics of giving, altruism and reciprocity 1" North Holland.

Kolstad, C. D., T. S. Ulen and G. V. Johnson (1990). "Ex-post liability of harm vs. ex ante safety regulations: substitutes or complements?" American Economic Review, 80(4): 888-901.

Nakamura, M., T. Takahashi and I. Vertinsky (2001). "Why Japanese firms choose to certify: a study of managerial responses to environmental issues" Journal of Environmental Economics and Management, 42: 23-52.

Oppenheim, A. N. (1992). "Questionnaire design, interviewing and attitude measurement" Pinter Publishers, London.

Pargal, S. and D. Wheeler (1996). "Informal regulation of industrial pollution in developing countries: evidence from Indonesia" Journal of Political Economy, 104(6): 1314-27.

Powers, D. A. and Y. Xie (1999). "Statistical methods for categorical data analysis" Academic Press Inc, New York.

Rugman, A. M. and A. Verbeke (1998). "Corporate strategies for environmental regulations" Strategic Management Journal, 19(4): 363-375. 
Segerson, K. and T. J. Miceli (1998). "Voluntary environmental agreements: good or bad news for environmental protection" Journal of Environmental Economics and Management, 36: 109-130.

Spector, P. E. 1992. Summated Rating Scale Construction. In: Basic Management. LewisBeck, M. S. (Ed.) Sage Publications. Newbury Park.

Udugama, J. M. M., U. K. Jayasinghe-Mudalige and G. H. I. Anjali (2011). Impact of environmental altruism on adoption of solid waste management practices in the firm: case of agri-food processing sector in Sri Lanka, Journal of Agricultural Sciences, 6(1): 32-44.

Udugama, J. M. M., U. K. Jayasinghe-Mudalige and G. H. I. Anjalee (2009) "Managers' environmental altruism and firms' compliance to national environmental management strategies: evidence from the food processing sector in Sri Lanka" Journal of Food and Agriculture, 2(2): 06-15.

Weersink, A., J. Livernois, J. F. Shogren and J. S. Shortle (1998). "Economic instruments and environmental policy in agriculture" Canadian Public Policy, 24(3): 309-327.

\section{Annex 1: Recommended Solid Waste Management Practices}

Being the largest manufacturing sector in Sri Lanka with more than 80 percent of firms operate in the provinces of very high population density (i.e. Western, Central, NorthWestern, Southern with more than 500 people per $\mathrm{km}^{2}$ ), the generation and unhygienic accumulation of waste through these agri-food processing firms has become a growing problem in Sri Lanka. As a solution to this problem, the Ministry of Environment (and Natural Resources then) [MENR], under the "National Strategy for Solid Waste Management", a set of environmental management controls with the characteristics of technology standards are recommended for the Sri Lankan food processing industry to minimize the accumulation of solid waste in the firm and reduce industrial pollution as a whole (1) "Sorting of waste based on 3R System" - establishment of necessary infrastructure facilities in appropriate places and allocating labor for the purpose; (2) "Composting" - the conversion of solid waste materials into composts, in which the heavy metal composition should be maintained below the recommended standards; (3) "Biogas technology" establishing units in accordance with the guidelines provided by the MENR; (4) "Biodegradable packaging materials" - using material such as paper, glass, cloth, etc. instead of polyethylene and other non-biodegradable plastics; (5) "Sanitary land filling" the maintenance of a site for which the firm should obtain clearance based on the guidelines provided by the Central Environmental Authority (CEA) in Sri Lanka; (6) a set of "Good Manufacturing Practices" (GMP); (7) Regular "Waste Auditing" system; and (8) ISO 14000 Environmental Management System. An individual business can select either one or a combination of these practices or any other appropriate mechanism that they deem to be effective in rectifying the problems associated with the generation of waste in their premises. 